\title{
Isolation, characterization and PCR multiplexing of polymorphic microsatellite markers in the edible dormouse, Glis glis
}

\author{
H. HÜRNER,* J. F. MARTIN,†A. RIBAS, $₫ \S A$. ARRIZABALAGA§ and J. R. MICHAUX*十 \\ *Laboratoire de génétique des microorganismes, University of Liège, Bât. B22, 27 Boulevard du Rectorat, Sart Tilman, 4000 Liège, \\ Belgium, +UMR 1062 CBGP, Campus international de Baillarguet, CS30016, F-34988, Montferrier sur Lez cedex, France, \\ $\ddagger I N R A$, UMR CBGP (INRA/IRD/Cirad/Montpellier SupAgro), Campus international de Baillarguet, CS 30016, F-34988 \\ Montferrier-sur-Lez cedex, France, §Museu de Granollers-Ciències Naturals C/Francesc Macià, 5108402 Granollers
}

\begin{abstract}
We isolated and characterized 10 dinucleotide microsatellite loci in the edible dormouse, Glis glis (Linnaeus). Four multiplex panels were developed. Loci were amplified in samples from two geographically distant populations (Torgny in Belgium and Montseny in Spain). All loci were polymorphic in Spain but four were monomorphic in Belgium. Individuals from Belgium and Spain exhibited an average allelic diversity of 1.9 and 3.3 and an observed heterozygosity ranging from 0.08 to 0.47 and from 0.04 to 0.72 , respectively.
\end{abstract}

Keywords: dormouse, Glis, microsatellite, multiplex, rodentia

Received 6 June 2008; revision accepted 25 July 2008

The edible dormouse, Glis glis (Linnaeus, 1766), is an arboreal and nocturnal inhabitant of deciduous and mixed forests in central Europe (Storch 1978). It is rare in many parts of its distribution particularly in the north where it is of conservation concern (Krystufek 1999). Here we report a set of novel polymorphic microsatellites that will be useful to describe the levels of genetic diversity and differentiation within and between populations, thus providing an initial genetic framework useful to identify conservation priorities and develop management strategies. We optimized these loci into four polymerase chain reaction (PCR) multiplexes.

Microsatellite screening was performed following A. Estoup and J. Turgeon (personal communication, see http:// www.inapg.inra.fr/dsa/microsat/microsat.htm for detailed protocol). Genomic DNA was extracted from a single individual and digested using RsaI restriction enzyme (Promega). A 500-900-bp fraction of the digested DNA was selected, purified and ligated to Rsa-21 and Rsa-25 linkers (Rsa-21 (5'-3') CTCTTGCTTACGCGTGGACTA; Rsa-25 $\left(5^{\prime}-3^{\prime}\right)$ phosphate-TAGTCCACGCGTAAGCAAGAG). The enrichment procedure followed the protocol from Kijas et al. (1994), based on streptavidin-coated magnetic particles (Magnesphere, Promega), with slight modifications. Both 5 -biotinylated $(\mathrm{TC})_{10}$ and (TG) $)_{10}$ oligonucleotides were used as probes. Enrichment products were then amplified with Rsa-21, purified and ligated into pGEM-T Easy Vector

Correspondance: Johan Michaux. Fax: 0032(0)43663840; E-mail: Johan.Michaux@ulg.ac.be
(Promega) then transformed into Escherichia coli competent cells (JM109, Promega). A total of 2103 recombinant clones were transferred on Hybond-N nylon membranes (Amersham). Colonies were hybridized at $46.5^{\circ} \mathrm{C}$ with the mixture of oligonucleotide probes (TC) ${ }_{10}$ and (TG) $)_{10}$ labelled with the DIG oligonucleotide tailing kit (Roche). A total of 435 positives clones were detected, 96 of which were sequenced using a BigDye terminator (Applied Biosystems) sequencing kit on an ABI310 (Applied Biosystems) automated sequencer. A total of 20 unique sequences containing clear repeated motifs were appropriate for designing primers. We designed pairs of primers using the Primer Designer Software (version 2.0, Scientific \& Educational Software 1990, 1991).

The 20 selected loci were first tested using monolocus PCRs. Ten of them provided good quality and polymorphic amplification products and were thus retained for multiplex PCRs. The forward primer of each locus was 5 '-end labelled with a fluorescent dye (FAM, HEX, NED). Based on size limitations and amplification specificity, we distributed the 10 microsatellites in four sets: set A $(G g 9, G g 13, G g 3)$, set B (Gg12, Gg14, Gg8), set C (Gg15, Gg11) and set D (Gg7, Gg16) (Table 1). Amplification of the four PCRs was performed on a Mastercycler ep-gradient-S (Eppendorf) using the Multiplex PCR kit (QIAGEN). The multiplex PCRs were conducted following Gauffre et al. (2007). All multiplex PCRs started with an initial activation at $95^{\circ} \mathrm{C}$ for $15 \mathrm{~min}$, followed by 35 cycles (set A and set D) or 30 cycles (set B and set C) of $30 \mathrm{~s}$ at $94^{\circ} \mathrm{C}$, annealing at $58^{\circ} \mathrm{C}$ (set A) or $63^{\circ}$ 
Table 1 Characteristics of 10 microsatellite loci from Glis glis with primer sequences, size of cloned allele, number of alleles (A), size range of PCR product, expected $\left(H_{\mathrm{E}}\right)$ and observed $\left(H_{\mathrm{O}}\right)$ heterozygosities with deviation from Hardy-Weinberg proportions $\left({ }^{*} P<0.05,{ }^{* *} P<0.01\right.$, $\left.{ }_{* * *} P<0.001\right)$ and null allele frequency (NAF) calculated by FreeNA software

\begin{tabular}{|c|c|c|c|c|c|c|c|c|c|c|c|}
\hline \multirow{2}{*}{$\begin{array}{l}\text { Locus } \\
\text { Accession no. }\end{array}$} & \multirow{2}{*}{$\begin{array}{l}\text { Primer sequence }\left(5^{\prime}-3^{\prime}\right) \\
\text { includes fluro-label dye }\end{array}$} & \multirow{2}{*}{$\begin{array}{l}\text { Repeat } \\
\text { motif }\end{array}$} & \multirow{2}{*}{$\begin{array}{l}\text { Size } \\
\text { (bp) }\end{array}$} & \multicolumn{4}{|c|}{ Belgium $(n=36)$} & \multicolumn{4}{|c|}{ Spain $(n=17)$} \\
\hline & & & & A & Size range & $H_{\mathrm{E}} / H_{\mathrm{O}}$ & NAF & $\mathrm{A}$ & Size range & $H_{\mathrm{E}} / H_{\mathrm{O}}$ & NAF \\
\hline Gg9 & F NED-GTTCAAATGTTTAGAGACTC & $(\mathrm{TG})_{18}$ & 189 & 2 & 188-194 & $0.21 / 0.22$ & 0 & 3 & $194-200$ & $0.25 / 0.16$ & 0.169 \\
\hline AM930996 & R-GTAAAGATGCTGATGAAGG & & & & & & & & & & \\
\hline Gg13 & F FAM-TCTATCCCTTGATCCTAG & $(\mathrm{TG})_{20}$ & 191 & 4 & 188-194 & $0.16 / 0.17$ & 0 & 4 & $188-196$ & $0.74 / 0.55$ & 0.061 \\
\hline AM930997 & R-CATGAAATGGGACTTCTTC & & & & & & & & & & \\
\hline Gg3 & F FAM-CACAACAGCCCATCATAC & $(\mathrm{CA})_{20}$ & 239 & 1 & 235 & - & 0.001 & 4 & $233-239$ & $0.68 / 0.55$ & 0.015 \\
\hline AM930998 & R-GATGGACGCATAATAATCG & & & & & & & & & & \\
\hline Gg12 & F HEX-CACAGCCCATCATTGACAG & $(\mathrm{CA})_{17}$ & 119 & 1 & 118 & - & 0.001 & 2 & $116-118$ & $0.54 / 0.42$ & 0.066 \\
\hline AM930999 & R-GTATTAGTTAGGGGTTTCCAGA & & & & & & & & & & \\
\hline Gg14 & F FAM-ATTTGGCTGGAGGTATAACTTG & $(\mathrm{CA})_{20}$ & 141 & 2 & $138-140$ & $0.28 / 0.22$ & 0.099 & 2 & $138-140$ & $0.32 / 0.17$ & 0.135 \\
\hline AM931000 & R-GGGTGTGAGGGGATGAAA & & & & & & & & & & \\
\hline Gg8 & F NED-CTATCGGGGACGGGTTTTG & $(\mathrm{CA})_{18}$ & 205 & 1 & 211 & - & 0.001 & 3 & $207-213$ & $0.44 / 0.50$ & 0 \\
\hline AM931001 & R-CTCCTGTTTCTTGCCAАTTCC & & & & & & & & & & \\
\hline Gg15 & F HEX-ССССТTСТСАААТTGTСТC & $(\mathrm{TG})_{21}$ & 146 & 1 & 145 & - & 0.001 & 4 & $141-147$ & $0.74 / 0.67$ & 0.062 \\
\hline AM931002 & R-GAATAAATAGGACTGGGGGT & & & & & & & & & & \\
\hline Gg11 & F HEX-GCCAGTGTGGTAACTTAG & $(\mathrm{CA})_{20}$ & 258 & 2 & $258-260$ & $0.18 / 0.08^{*}$ & 0.056 & 5 & $252-260$ & $0.74 / 0.39^{* *}$ & 0.215 \\
\hline AM931003 & R-GATTCATGTTTGAGCTATTACC & & & & & & & & & & \\
\hline Gg7 & F HEX-CCACATCTGACCCCAAAC & $(\mathrm{TG})_{21}$ & 205 & 3 & $202-210$ & $0.50 / 0.33$ & 0.064 & 4 & $202-210$ & $0.66 / 0.72$ & 0 \\
\hline AM931004 & R-GAGGATCACAGGTTGAGGA & & & & & & & & & & \\
\hline Gg16 & F NED-CTTTCCTTCCCTGTTTGTCTC & $(\mathrm{TG})_{18}$ & 122 & 2 & $127-129$ & $0.44 / 0.47$ & 0 & 2 & $129-133$ & $0.22 / 0.04^{* *}$ & 0.157 \\
\hline AM931005 & R-GGGGATGGTAGAATGCCTC & & & & & & & & & & \\
\hline
\end{tabular}

- not enough alleles to perform HW test.

(set $\mathrm{B}$, set $\mathrm{C}$ and set D) for $90 \mathrm{~s}$, extension at $72{ }^{\circ} \mathrm{C}$ for $60 \mathrm{~s}$ and final extension of $60^{\circ} \mathrm{C}$ for $30 \mathrm{~min}$. The PCR products were detected using a monocapillary ABI PRISM 310 Genetic Analyser (Applied Biosystems). Null allele frequency (NAF) was determined using the expectation maximum algorithm (EMA) (Dempster et al. 1977), and the $F_{\mathrm{ST}}$ values were then adjusted accordingly in FreeNA (Chapuis \& Estoup 2007).

We tested the four microsatellite sets on 36 G. glis trapped in Torgny (southern Belgium) and on 17 G. glis trapped in Montseny National Park (northern Spain). All loci were polymorphic in the Spanish populations but four were monomorphic in Belgium (Table 1). Individuals from Spain and Belgium exhibited an average of 3.3 and 1.9 alleles per locus, ranging from two to five and one to four, respectively. The small number of alleles observed in Belgium may be due to genetic drift and inbreeding because these populations are fragmented and small in size. Exact tests performed using Arlequin 2.0 program (Schneider $e$ al . 2000) revealed significant deviations from Hardy-Weinberg equilibrium for locus $G g 11$ in Belgium and for two loci ( $G g 11$, Gg16) in Spain. Both loci exhibited a deficit in heterozygotes, indicating the possibility of null alleles (Table 1). The values of NAF were always $\leq 0.2$ (except for Gg11), indicating that null alleles are not expected to cause significant problems in the analysis (Chapuis \& Estoup 2007). Therefore, we only considered locus $G g 11$ (NAF $=0.215$ ) to be potentially problematic. When correcting allele frequencies for putative null alleles, we found that the presence of null alleles did not change the outcome of the statistical test of differentiation between two populations $\left(F_{\mathrm{ST}}\right.$ not using $\mathrm{EMA}=0.58$ and $F_{\mathrm{ST}}$ using EMA = 0.57). After Bonferroni correction, no significant linkage disequilibrium was detected using Fisher's exact test conducted in GenePop (Raymond \& Rousset 1995). In conclusion, these first microsatellite primers developed for G. glis will provide necessary and powerful molecular tools for management and conservation studies in the future.

\section{Acknowledgements}

We are grateful to Alec de Selliers de Morenville for his financial support. We thank the CBGP for welcoming us during the laboratory work. H. Hürner is supported by a Belgian research fellowship provided by the FRIA (FNRS). We are also grateful to Montseny Natural Park that provided financial and logistical support for the nestboxes in Spain.

\section{References}

Chapuis M-P, Estoup A (2007) Microsatellites null alleles and estimation of population differentiation. Molecular Biology and Evolution, 24 (3), 621-631. 
Dempster, AP. Laird NM. Rubin DB (1977) Maximum likelihood from incomplete data via the EM algorithm. Journal of the Royal Statistical Society B: Biological Sciences, 39, 1-38.

Gauffre B, Galan M, Bretagnolle V, Cosson JF (2007) Polymorphic microsatellite loci and PCR multiplexing in the common vole, Microtus arvalis. Molecular Ecology Notes, 7 (5), 830-832.

Kijas J, Fowler J, Garbett C, Thomas M (1994) Enrichment of microsatellites from citrus genome using biotinylated oligonucleotide sequences bound to streptavidin-coated magnetic particles. BioTechniques, 16, 657-662.

Krystufek B (1999) Glis glis (Linnaeus, 1766). In: The Atlas of European Mammals (eds Mitchell-Jones Jet al.), pp. 294-295. Poyser Natural History, London.

Raymond M, Rousset F (1995) GenePop: population genetic software for exact tests and ecumenism. Journal of Heredity, $\mathbf{8 6}$ 248-249.

Schneider S, Roessli D, Excoffier L (2000) Arlequin, version 2.0. a software for population genetics data analysis. Genetics and Biometry Laboratory. Department of Anthropology. University of Geneva, Geneva, Switzerland.

Storch C (1978) Glis glis (Linnaeus, 1766) - Siebenschläfer. In: Handbuch der Säugetiere Europas (eds Niethammer JB and Krapp F), pp. 243-258. Akademische Verlagsgesellschaft, Wiesbaden, Germany.

doi: 10.1111/j.1755-0998.2008.02365.x

(C) 2009 The Authors

Journal compilation (C) 2009 Blackwell Publishing Ltd

\title{
Sixteen polymorphic microsatellite markers from Zizania latifolia Turcz. (Poaceae)
}

\author{
ZHIWU QUAN,${ }^{*}$ LEI PAN,${ }^{*}$ WEIDONG KE, + YIMAN LIU + and YI DING* \\ *Key Laboratory of MOE for Plant Development Biology, College of Life Sciences, Wuhan University, Wuhan 430072, China, +Wuhan \\ National Field Observation E Research Station for Aquatic Vegetables, Wuhan 430065, China
}

\begin{abstract}
Sixteen polymorphic microsatellite markers were isolated and identified inZizania latifolia Turcz. (Poaceae), a perennial aquatic plant widespread in Eastern Asia. The microsatelliteenriched library was constructed using the fast isolation by AFLP of sequences containing repeats method. These markers revealed two to 14 alleles, with an average of 5.6 alleles per locus. The observed and expected heterozygosities varied from 0.071 to 0.690 and from 0.174 to 0.812 , respectively. These markers will be useful for studying of gene flow and evaluating the genetic diversity of the Zizania latifolia population.
\end{abstract}

Keywords: genetic diversity, microsatellite, wild rice, Zizania latifolia Turcz.

Received 18 July 2008; revision accepted 30 July 2008

The Zizania, also known as 'wild rice', belongs to the tribe Oryzeae. The genus Zizania consists of four species, including Zizania aquatica L., Zizania palustris L., Zizania texana Hitchc. and Zizania latifolia Turcz. The first three are found throughout North America, known as Canadian wild rice, American wild rice and Texas wild rice, respectively; in contrast, Z. latifolia Turcz. is widely spread throughout Eastern Asia (Hass et al. 2003; Guo et al. 2007). The species Z. latifolia Turcz., is a perennial aquatic plant grown in lakes, ponds and wetlands, and its flowing can be abolished by epiphyte Ustilago esculenta infection (Guo et al. 2007). As a popular aquatic vegetable, Z. latifolia has been cultivated for more than 2000 years, and is distributed widely in the

Correspondence: Yi Ding, Fax: 86-27-68754319;

E-mail: yiding@whu.edu.cn eastern and southern areas of China. Although wild populations of Z. latifolia are important genetic resources for vegetables and forage, very limited research on population structure and conservation of Z. latifolia has been reported. One previous study has assessed the genetic diversity of Z. latifolia using Adh1a gene sequences (Xu et al. 2008), but no microsatellite markers have been reported for Z. latifolia. Importantly, microsatellite markers are reliable tools for investigating population structure. Here we report the isolation and characterization of microsatellite markers designed for Z. latifolia.

Total genomic DNA was extracted from tender leaves using the cetyltrimethyl ammonium bromide method (Murray \& Thompson 1980). The microsatellite-enriched library was constructed following the fast isolation by amplified fragment length polymorpshim (AFLP) of 